\title{
Later life ICT learners ageing well
}

\author{
By HeLen RusSelL
}

\begin{abstract}
This article is based on a qualitative study of later life computer learners and their learning experiences in Sydney, Australia. Participants who undertook lessons from peer tutors in non-formal learning environments were aged between 63 and 86. Sixteen later life learners were interviewed individually by using hermeneutic phenomenological methodology. The use of semi-structured interviews provided opportunities for participants to elaborate and reflect on their learning and lived experiences. The interviews took place over a period of seven years, from 2003 to 2010. The main aim of the study was to understand and interpret the lived experiences of information and communication technology (ICT) learning in later life. Interpretations from the study suggested that learning and using a computer contributed to a sense of well-being, furthered an understanding of the lifeworld and provided participants with a heightened sense of belonging. In this article, well-being is discussed in the context of ageing and learning in a modern developed country. The ontological and existential themes of being, becoming and belonging are explored and used as a framework to interpret the findings from the study.
\end{abstract}

Keywords: later life, learners, well-being, ontological, existential.

* Helen Russell, Faculty of Arts and Social Sciences - Education, University of Technology Sydney, Australia 
International Journal of Ageing and Later Life

\section{Ageing Well}

People older than 70 years have lived through many historical, cultural and technological changes, possibly more than any other age group in our time. The world has changed so rapidly that older retirees may experience a very different world from that in which they grew up and grew older. Hence, for the current cohort of older adults, there has been a lifelong imperative to adapt to change in order to meaningfully participate in society. The individual lifeworld and lived experience include the ontological existentials of time, space, corporeal and relations. How we feel about ourselves and our quality of life as we age are grounded in these four ontological concepts. The ontological nature of ageing well means that humans need to position themselves to respond to the changes in their own way, to use the changes to their advantage and to choose what is relevant and meaningful to their lives.

In a study of adults aged 82-92, six dimensions of quality of life were revealed, "relationships, activities, health, philosophy of life, the person's past and present lives, and future perspectives" (Borglin et al. 2005: 203). In a similar study with people aged between 77 and 87, it was found that "material values became less important and that social relations and spending time by oneself became more important" (Borglin et al. 2005: 203). In considering these two studies, it may appear that within older adulthood values change and that there is no single description of well-being in later life. Health-related concerns, such as the "transition from health to infirmities," may provide a way of interpreting the changes (Borglin et al. 2005: 203). It seems reasonable to assume that as people experience age-related physical and mental decrements, their priorities and values and sense of well-being would shift to a more practical level of what they are able to do and not do.

The lived experience of transitioning from independence to dependence may also provide an affective dimension to a sense of well-being. The fear that there may be a loss of control of body and mind could undermine an older person's sense of "all's right with the world." As dependencies and perceived loss of control are negotiated, older people need to feel that they have choices. Even though the number of older adults purchasing and learning to use computers is increasing in developed countries, many older adults do not purchase and learn to use a computer. However, 
it is recognised by some researchers that in order to remain autonomous, older people will need to use technological applications and digital devices (Slegers et al. 2007). Those with little or no experience in using technology or a dislike of technology may feel that they are having technology thrust on them.

Within the choices of older adulthood, persons seek to recognise the self, that is, the person they believe themselves to be, and this knowledge would assist in coming to terms with a dependency or change. Remaining in control throughout life is viewed as a prime motivator in adult intentions (Wolf 1998). The importance of maintaining a sense of continuity and integrity of the self enables older people to recognise oneself as not having fundamentally changed, despite a loss of independence. People born early in the 20th century have lived through a majority of technology inventions and their lives parallel the history of technology. In developed countries, the available technologies require "constant adaptive change" (Candy 1991: 20). The current cohort of older adults is faced with learning to use a range of digital devices that may become necessary for independent living or ageing-in-place. The acceptance of new challenges "may be key to staying fully functional and maintaining a high quality of life" (Mynatt \& Rogers 2001: 25).

Adapting to changes requires a sense of the future, forward thinking rather than living in the past:

\footnotetext{
Maintaining certain objectives and perspectives on the future, and the existence of efforts to achieve them, is something that we not only maintain as we get older, but also appears to be an important determinant of well-being in old age.
}

(Hernandez-Encuentra et al. 2009: 242)

It is believed that those who fix their view on the future are better able to "adapt to the changes that take place around them" (Blit-Cohen \& Litwin 2004: 396). Adapting to changes also applies to changes in the body and mind, from health to frailness, from independence to partial dependence, from control to loss of choice and control. However, in describing the shift in what constitutes well-being in later life, older adults are demonstrating that they are able to adapt to change and to set their sights on the future in a realistic and meaningful way, and 
International Journal of Ageing and Later Life

importantly, while they are maintaining a sense of continuity and a recognition of the self, "an experience of a preserved self" (Borglin et al. 2005: 215).

Older adults are faced with significant challenges as they learn to use new technologies. The difficulties in unlearning old ways of doing things and devising new strategies to compensate for perceived deficiencies of an ageing body and mind will possibly also require "new learning of an unfamiliar mechanism" (Blit-Cohen \& Litwin 2004: 386). Learning strategies used in the past may not be relevant to learning with the digital devices of the 21st century. As older adults devise new learning strategies, they are also learning to operate new technologies.

Older adults respond to disorienting dilemmas with a heightened awareness of longevity, and they seek equilibrium to resolve the tensions unique to older adult life. This can be resolved by seeking meaning through learning (Jarvis 2001).

Learning forces the self into a continual reflexive state that is "ontologically and existentially directed" (Kidd 1973: 5). This means that learners face questions relating to the self that require reflection and understanding of the self. Kidd (1973) furthers an understanding of the self and the nature of learning by proposing a triad of being-becomingbelonging that is situated in the ontological and future-directed nature of learning. As a human being, we are always becoming, not in a selfish pursuit, but striving towards individual and social goals (Kidd 1973). Becoming refers to the purposeful activities carried out to achieve personal goals, hopes and wishes to promote the improvement or maintenance of knowledge and skills, and to cope with changes (Centre for Health Promotion 2010). However, without the belonging component, beingbecoming would remain individually located and self-centred, and Kidd believed belonging is what gives learning its real meaning. Frankl (1984: 133) illuminated this aspect of the being when he referred to the location of the true meaning of life as outside the being. "The true meaning of life is to be discovered in the world rather than within man or his own psyche as tho it were a closed system". The importance of Kidd's belonging element to the being-becoming dualism is augmented by Frankl, who stated that "being human always points, and is directed, to something, or someone, other than oneself" (Frankl 1984: 133). 
The ontological questions raised by Kidd's being-becoming-belonging notion are, "Who am I? What do I want for myself? Where am I going? How will I get there? When will I get there? Where do I belong?". According to Kidd (1973: 9), learning is about self-discovery, self-expression and fulfilment, and involves a search for that part of the being that is truly human. In answering the ontological questions, humans have a greater understanding of themselves, that is, their own being. In a similar notion to Allport's (1955) belief that the more we know about the self the more we know about the whole human race, Rogers (1969) asserted that the deeper the being delves into the self to find the unique, the more they find the whole human race. Kidd (1973) believed that it is not enough to have insights without meaningful relations with others and that it is the relationship (belonging) factor that makes learning meaningful.

For older adults, the "adoption of new technologies requires learning new skills, new ways of performing familiar skills, new procedural knowledge and a new lexicon" (Czaja et al. 2006: 348). The technical jargon may be of particular difficulty for older adults.

Older adult computer learners face serious learning difficulties in an unfamiliar and unique computer environment (Hrimech \& Bouchard 1998; Moody 1986). In a world of many changes over a lifetime, the current cohort of older people has been challenged many times to integrate new ways of thinking and doing. The affective nature of learning, such as feelings of self-confidence and self-efficacy in taking on new challenges, may contribute to the overall sense of well-being.

There is a further affective component and that is the way those in later life experience the technology, and this can be related generally to past experiences, self-efficacy and personal achievement with technology. "The use of technology brings experience of use that has a key role in the affective and emotional dimensions beyond usability" (HernandezEncuentra et al. 2009: 240). This means that the technology is more than a physical object playing a functional role. The technology provides users with feelings and affects, which indicate a subjective and personal experience that transcend the way the technology is used. The emotional experience of using a device includes a range of feelings such as "sensations, perceptions, feelings, expectations, values, satisfaction, or 
International Journal of Ageing and Later Life

frustration" (Hernandez-Encuentra et al. 2009: 240). The users have a relationship with the technology grounded by the purposes for its use and the emotions they experience when using the technology. They have an affective involvement with the technology, because they have an emotional response when using a particular technology. Further, they have a deeper understanding of the technology, because they have experienced a range of affective and emotional dimensions.

The learning experience of older people and their sense of achievement may be heightened by the notion that learning to use new technologies is perceived by the learners as being difficult and cognitively demanding. Older people have less confidence in their ability to use computers than do younger people in learning to use and operate current technologies (Czaja et al. 2006: 333). This seems to suggest that when older people persist with their learning, despite experiencing barriers, they achieve a stronger sense of pride in their accomplishments and more confidence in their abilities with technologies.

Common terminology to describe ageing well is couched in positive terms and centres on the dual notions of continued meaningful participation and decreased marginalisation. Descriptions include active ageing (WHO 2002), satisfactory ageing (Kelly 1993), successful ageing (TSAO Foundation 2004) and well-being (Organisation for Economic Co-operation and Development (OECD) 2001, 2003).

The World Health Organization (WHO 2002) described active ageing as the process of optimising opportunities for health, participation and security in order to enhance the quality of life as people age (WHO 2002). Kelly (1993) articulated two dimensions that are important to the notion of activity within satisfactory ageing: those of quality of relationships and regular engagement in activity. When the quality of relationships and regular engagement in activity dimensions are combined, such as when the activity is the context of the relationship, and communication and sharing with others are a central component of the activity, there is more likelihood of higher life satisfaction (Kelly 1993). This combination, of relationship and activity, is relevant to the computer learners in the current study who used computer knowledge and skills to improve and increase communication with younger members of their family. 
Interdependence and intergenerational solidarity are considered important tenets in active ageing, so it is acknowledged that the two-way giving and receiving between people means that both parties are able to experience autonomy. It is in the mutual transfer of knowledge that both are able to make decisions. This relationship enables reciprocity and autonomy, as well as a sense of belonging. In an active ageing policy document (2002), the WHO defined autonomy as the perceived ability to control, cope with and make personal decisions about day-to-day life, within the context of family, friends and neighbours. This means that people are able to choose these two aspects of interdependence and autonomy in such a way that it assists them in their lifeworld. It is also important that people believe they are able and capable of making autonomous decisions. The "rapid rate of political, social and technological change necessitates the need for autonomous people" (Candy 1991: 20). As people age, their quality of life is largely determined by their ability to maintain autonomy and independence (WHO 2002). Thorson (1978) presented two criteria as developmental tasks of ageing that place them within the autonomy dimension. These are maintaining control and avoiding helplessness. The OECD (2001) identified acting autonomously as one of the three key competencies essential for the personal, social and economic development and well-being of people in modern complex societies.

The choice between interdependence and autonomy enables older adults to maintain and pursue the being-becoming-belonging of learning. They are able to answer the existential and ontological questions of the being by creating the lifeworld of their choice, according to their needs. These needs may change as they age, but underpinning this is the strong sense of "integrity and continuity", that is, the desire to continue to be the person they recognise as themselves.

There are benefits to all generations in intergenerational exchanges and relationships. Erikson et al. (1986) suggested that the inter-generational interdependence opportunities were unique to this stage of life, and that they contributed to the psychosocial developmental second last stage (passing on cultural and historical artefacts and wisdom). Thorson (1978) also included perpetuating the culture as one of the eight developmental tasks of ageing. 
International Journal of Ageing and Later Life

Continued participation as a dimension of well-being was identified in the literature by several authors. These authors referred to the essential aspects of ageing well in various ways. Thorson (1978) referred to the concept of ongoing participation as remaining integrated in society, Erikson and colleagues (1986) as vital involvement and both Kelly (1993) and the TSAO Foundation (2004) described regular engagement in activity as a dimension of well-being. Participation enhances the quality of life of people as they age (WHO 2002).

Interest in life generally as a dimension of well-being in later life is closely related to the previous section of continued participation. The notions of vital involvement (Erikson et al. 1986), remaining integrated in society (Thorson 1978) and regular engagement in activity (Kelly 1993, TSAO Foundation 2004) suggested that there was a link between continued participation and interest in life generally.

The OECD (2001 and 2003) identified three key competencies essential for the personal, social and economic development and well-being of people in modern complex societies as: interacting in socially heterogeneous groups; acting autonomously; and using tools interactively. All three key competencies contribute to the well-being of older adults in the socio-cultural context of the lifeworld, grounded by the existential concept of time. In the time dimension, older adults are acutely aware that they have a limited number of years left to live and they want to make the most of them.

Of particular relevance to the study of older adult computer learners is the notion of using tools interactively. The OECD (2003: 5) stated that:

Using tools interactively does not simply mean having the technical skills to use a tool (e.g., read a text, use computer mouse, etc), but assumes a familiarity with the tool itself and an understanding of how the tool changes the way one can interact with the world and how the tool is used to accomplish broader goals.

The OECD further stated that the key competency of using tools interactively requires "mastery of socio-cultural tools such as language, information, and knowledge" (2003: 5). Within the lifeworld of older adults being able to evaluate tools for specific purposes and being able 
to "talk the talk" of digital speak are as important as having the skills of using digital tools. It is further suggested that "new technological innovations require unfamiliar technology implementation" (Mahmood et al. 2008: 109).

The terminology for ageing well suggested that with choice, independence and good health, there will be benefits to the individual. Further, that family would benefit by acknowledging and encouraging the experience and wisdom of people in later life. The descriptions also included the notion of the flow-on effect of benefit to the community, locally and globally. Benefits include less financial dependence on governments for assistance, housing and health-related costs. The community as a whole may also benefit by being inclusive of diversity and more cohesive.

\section{The Research Design}

\section{Participants}

Five male and 11 female information and communication technology (ICT) learners, with ages ranging from mid-60s to mid-80s (as at 2003), were interviewed at least twice over a period of seven years, from 2003 to 2010. An approach was made to non-profit organisations that offered lessons for older adults and learners volunteered to take part in the study. The main aim of the study was to understand and interpret the lived experiences of ICT learning in later life. Participants were learning to use technology either in small class settings with peer tutors or in their own home with an individual peer tutor. Peer tutors were voluntary and not qualified teachers. On average, each learner attended weekly lessons for a period of 12 months. The initial interviews took place during the period of learning and then participants were further interviewed when they had ceased lessons. All participants had retired from paid work and identified themselves as older adults. Quotes from the following 15 of the 16 participants are given in this article. Pseudonyms have been used to protect the identities of participants. 
International Journal of Ageing and Later Life

\begin{tabular}{llc}
\hline Name & Gender & Age \\
\hline Alex & Female & 73 \\
Andy & Male & 82 \\
Aub & Male & 86 \\
Bobby & Female & 70 \\
Clem & Female & 81 \\
Coby & Female & 82 \\
Gill & Female & 77 \\
Henk & Male & 81 \\
Hilary & Female & 77 \\
Kerry & Female & 63 \\
Merv & Male & 72 \\
Morgan & Female & 82 \\
Pat & Female & 68 \\
Quentin & Male & 64 \\
Sunny & Female & 78 \\
\hline
\end{tabular}

\section{Methodology}

A hermeneutic phenomenological methodology was chosen, because it enabled rich existential and ontological insights into the learning experience by privileging the voices of the participants. Ontological insights were interpreted from the lived experience of the participants, whereby questions of the being's relationship with the world were explored. Understandings of phenomenology and hermeneutics were influenced by the work of Heidegger (1962) and his ontological "account of the human-world relations which determine and outline the dimensions of human existence (Dasein)" (Ihde 1990: 23). Heidegger's link with ontology influenced an orientation to phenomenology and enabled a focus on the being's relation with the world and the nature of lived experience.

\section{Research Questions}

1. What is the nature of the learning experience?

2. What interpretations do learners place on their learning experience?

3. What are the outcomes of the learning experience? 


\section{Analysis}

Three phenomenological, analytical and interpretive tools were used at various times throughout the analysis and interpretative phase. The three tools were within-case, cross-case and thematic analysis. Withincase analysis focussed on the individual participant's learning and enabled insights into the ontological experience, that is, those elements that seek to answer being questions. Narratives as told by the participants in the interviews were constantly examined, comparing them to other stories told by the respondent and also comparing them to stories told by other participants in cross-case analysis. Data from within-case and cross-case analysis were placed within a thematic framework so that the data could be examined and referenced as emerging themes. Various understandings such as a priori understanding (based on the literature review), emerging understanding (based on field data), and analytical understanding (based on recurring data in within-case and cross-case analysis were used.

\section{Results from the Study}

The results from the study indicated that within the being-becomingbelonging triad, several phenomenological themes emerged. These themes will be explored as follows: the being dimension encompassed two themes, personal achievement and self-confidence. In the becoming dimension, three themes emerged, adaptive capacity, autonomy and using tools interactively. Within the belonging dimension, three themes emerged, quality of relationships, continued participation and interest in life generally.

\section{Being}

The being domain is centred on the ontological and the affective nature of learning; focusing on the question of "Who am I?". Devoid of work titles and roles and no longer defined by work/social role, older adults look to other sources to answer ontological questions. Participants in the study grounded their learning by referring to personal achievements and a sense of confidence. Learners did not need extrinsic confirmation of achievement (not that they rejected it, but they considered it "icing on the 
International Journal of Ageing and Later Life

cake," always nice to have a loved one say, "well done" or by being able to show someone you have regarded as an expert a new technique, strategy or function). Later life computer learners in the study did not need rewards or certificates; they knew when they had "done well".

Personal achievement. The way that older people experience technology is an important component of learning to use a particular digital device. This new learning experience can be related to past experiences, selfefficacy and personal achievement with technology generally.

The satisfaction that is derived from accomplishment in retirement, particularly because it is freed from the work-related paradigm of external reward, provided an opportunity to derive satisfaction on the basis of intrinsically experienced adequacy. Being able to use a computer gave Alex "a lot more depth" in her life, including having more to talk about with friends, and the ability to produce computer-based documents, such as newsletters, flyers and posters for her various social clubs.

For Quentin, the greatest sense of personal achievement came after frustrations and perseverance. His graphic account described next attests to the feelings of despair and joy in his attempts to complete a task on the computer:

\footnotetext{
I feel a great sense of satisfaction when I finally manage to do something after running into brick walls. A couple of weeks ago I made an order for an anti-virus program over the net. I was lacking confidence in doing it myself but I thought, "Well, I've got to do it", but I wasn't real sure how to do it. Anyway in the end, I went into it. Half way through it I got into a panic because it asked for my serial number and I couldn't find it. I didn't realise you could switch from one program back to another to find it. I had already given my name and address and bank card number. I panicked and then I aborted the whole thing. I switched the computer off. I tried to make a phone call to the help line but they closed at $5 \mathrm{pm}$ and this was $8 \mathrm{pm}$. Right, I decided, I have to go through with this; it's not going to get the better of me. So I turned the computer back on and had another go, starting from the beginning again. I entered in all the information for a second time and followed the cues and finally came to the end and saw the word "SUCCESS", flash up. I thought, "Right, well I can do something" (Quentin)
}

Pat experienced a "high" in achieving a self-set task, a specific learning need she identified. It also affirmed her belief in her learning capability at a crucial time: 
I had all these play files just sitting around and I said to my son-in-law, "I really need to get rid of all this, I can't just keep opening new files", so he showed me how to delete them all and I went home and I did it. And it all worked and I thought, "Oh, thank goodness, I've learnt something." (Pat)

The sense of achievement assisted learners in the positive construction of themselves as computer learners. This enabled them to be more optimistic for future learning achievements, more inclined to be curious, more confident to explore and more able to cope with difficulties.

Some participants from the study described progress in measurement terms, in tangible ways, and others referred to greater confidence as a sign of progress. Quentin's comment captures the complex nature of achievement, progress and self-confidence:

\footnotetext{
I think back and realise that I am doing things on the computer that previously I had no idea about. I am able to do many things now that I'd never even dreamed of. I even feel more confident in offering advice to friends about certain [computer] exercises. (Quentin)
}

In a combination of affective and cognitive domains, Quentin related personal achievement to a sense of making progress, feeling good and being confident. The increased confidence came about from seeing a product and an outcome from learning as well as a sense of personal achievement.

Self-confidence. An important aspect of a sense of well-being is the belief that participation, active involvement and acting autonomously are possible. The notion of self-confidence, of how the self is constructed and whether this is affirmed or not by others, emerged as a theme in the analysis of the study. Participants in the study referred to greater self-esteem and self-confidence as a result of learning to use a computer. When they achieved something that had been difficult to master, they experienced an invigorated sense of self-achievement, at times elation, and a belief in their continued ability to learn. Their sense of capability was reinforced and affirmed when they were asked questions by others, and they were able to participate and contribute in discussions (especially if these were mixed-age groups) and when they were asked to assist 
International Journal of Ageing and Later Life

with tutoring beginning learners. Alex described her experience in the following way:

I came back to help with beginners this year and the fact that I was able to solve a problem means I've progressed in my learning. The beginners couldn't do it, but I could. I hadn't realised that I've got more knowledge than I thought I had by listening to other people's problems and thinking, "That's not a problem for me". I know how to. (Alex)

Alex also experienced self-confidence in another way, by being able to contribute to discussions in a mixed-aged group. Alex believed that her familiarity with computers and the terminology associated with technology provided her with knowledge that crossed over age barriers. Despite being in her 70s, Alex did not feel that age was a consideration when in technology conversations with younger people.

Clem mentioned the iterative effects of greater self-confidence and the link with personal achievement. "[Learning to use the computer] gets easier the more you can do. You are more confident to try new things, to experiment" (Clem). The more Clem was able to achieve, the greater her confidence was. This led to trying new things and experimenting and, in turn, increased her confidence and sense of personal achievement.

\section{Becoming}

The nature of the changing world in which those older than 70 have lived provides the backdrop and a link with the being. Within the context of a technologically dense world, participants reconciled their lived experiences with the being. For this current cohort of older people, the beingbecoming duality is of greater significance than for other age groups. Technological advances and rapid obsolescence result in totally new ways of doing things in everyday living and may present older adults with the challenge of facing learning that is significantly unfamiliar to them.

Adaptive capacity. Adaptive capacity is the ability to adapt to unfamiliar learning techniques and to technology generally. Participants in the study alluded to the strangeness of the computer learning environment, particularly how computers occupied the learning space and how they (as learners) would physically and psychologically position themselves 
within the learning space. For older people, the newness of the learning environment and the unfamiliarity of the computer learning environment required an openness to change and a need to adapt. Without the capacity to adapt, they may not be able to learn. Hilary described the difficulty with learning to use a computer. "The techniques are strange. Something you wouldn't have thought of 20 years ago. It's not like anything you've learnt before" (Hilary).

A number of participants in the study were competent typists with extensive experience in using manual typewriters. They were amazed and thrilled with the various functions of the word processing programs in being able to delete, backspace, change styles and save the file. They acknowledged the keyboard differences in the computer and the typewriter, but regarded the computer more highly. Participants mentioned the light feel of the keyboard and the absence of needing to correct an error. The ability to adapt to the technology in such an enthusiastic way encouraged learners to use a wide variety of functions not available on a typewriter, such as macros, autocorrect, word wrap, fonts and colours. The learners acknowledged the necessity to adapt, if they were going to achieve success, and they created and constructed new horizons, by learning new things, exploring and being curious. They were not fixed or rigid in their learning strategies, and they adapted to suit the context.

In a world of great technological change, older adults need to adapt to a new world order and to find new expressions for their lifetime of skills and knowledge. For older people, the newness and unfamiliarity of the computer learning environment required an openness to change and to adapt. A number of participants mentioned doing things differently since learning to use a computer that demonstrated their capacity to adapt. Andy paid bills online rather than in person; Quentin had more frequent contact with friends, but wrote fewer letters; Kerry used electronic spreadsheets instead of paper-based ledgers; Morgan checked tide times online; and Clem no longer bought the daily newspaper, preferring instead to read it online. The older adult participants adapted to the technology in ways that suited their specific needs.

Autonomy. Alex, Coby and Quentin referred to their pride in the ability to create personalised greeting cards for friends and family. Bobby was able to type official-looking letters in relation to investments. Andy used 
International Journal of Ageing and Later Life

the Internet for banking and paying bills to avoid standing in queues. Quentin looked ahead to the future to a time when he will be physically incapable of doing his own shopping. When this happens, he believes he will be able to shop online without having to ask friends to help out. The knowledge of the avoidance of future dependency was important for Quentin to maintain his lifestyle and to control his lifeworld.

Andy, with failing eyesight, was able to increase the size of the fonts on the computer so that he could read newspapers, newsletters and notices. Without this facility, to increase the print size, he would be unable to continue reading. Andy's experience demonstrated that the perceived benefits to him were not only autonomy but also of maintaining interest in life in general with the ability to participate meaningfully. Andy was able to stay in touch with what was happening without having to rely on other people for news. Bobby was also able to stay in touch by reading the news in her first language without having to travel to her country of birth. This link with her past was very important to her as she had little contact with relatives and friends from her homeland.

Both Clem and Kerry talked about one of their children having a serious illness and being able to use the Internet to find out more about the illness. They were able to increase their knowledge and understanding of the illnesses by acting independently. The information they gleaned from their research was then used to assist them in coping with their child's illness and in discussions with their child. Clem and Kerry's ability to use the computer as a research tool and a source of information enabled them to be more informed and better able to participate and contribute in discussions and making decisions.

Gill was a volunteer gardener for a residential village and liked to know about the plants she helped to cultivate, particularly little-known species. "It's nice to know what these plants are. So I look them up on the Internet. Brilliant. Google. Fantastic. Always wanted to know these things" (Gill). The ability to independently search for information about a subject she loved gave her much pleasure and reinforced her love of the computer. She also believed that in the future she would be able to find out anything she wanted to know.

Aub was increasingly becoming house-bound. He had difficulty hearing and had recently relinquished his driver's licence. Aub had a volunteer 
home tutor for computer lessons and was reliant on assistance with shopping and cleaning. He used the computer to write his life story and to use the Internet. His primary use of the Internet was in finding out what happened to the people he served with in the defence forces, particularly during the war:

\footnotetext{
I often use the Internet to get on to the Australian War Museum. Through that I have found a lot of my friends or relatives or people that I trained with and I can look up the Nominal Roll and it will tell you what happened to them. That fills in a certain thing and it sounds like a bad expression, but it gives me satisfaction. Not because they got shot down but at least I know what happened to them and be able to use the computer and know where they are. (Aub)
}

Aub was increasingly dependent on other people for his physical needs but being able to use the computer to fill in the missing pieces of his life gave him much satisfaction. He was able to make contact via email with some of the people from his past life, and he scanned a number of photos and sent them as attachments. Despite his physical dependency, Aub's sense of autonomy was still high because of his ability to use technology to stay in touch with loved ones. Without this technology, Aub's life would be very different.

Using tools interactively. In a world where digital technology has replaced manual tools and appliances for domestic use, commercial use and entertainment, the skills of being able to use digital technology is an imperative. Using tools interactively is recognised as being one of the key competencies of well-being for adults in modern complex societies. To be without the skill is to be at a disadvantage and increases the potential for being marginalised. Participants in the study were increasing their ability to use computers by attending lessons and using computers on an almost daily basis. They accepted that the world was not the same as the one they had known most of their lives and that in order to keep-up with the rest of the world they had "to go with the times".

\section{Belonging}

Within the domain of belonging, three areas were identified and influenced by literature from the Centre for Health Promotion (2010). Personal 
International Journal of Ageing and Later Life

belonging includes the person's fit with the living environment, and the connections with physical environments such as home, neighbourhood and community. Social belonging includes the sense of acceptance by intimate others, family, friends, neighbourhood and community. Community belonging represents access to resources normally available to community members, such as community activities. These three belonging dimensions (personal, social and community) were analysed and interpreted in this study as quality of relationships, continued participation and interest in life generally.

Quality of relationships. Beginning with the closest relationship, the family, older adults experienced increased communication, based on technical discussions, with intergenerational members. The current older adults provided role models for future generations of the capabilities of older adults and the potentialities of development throughout life. Future generations were learning what life could be for them as they age. For younger people, the close association with an older adult breaks down the stereotype of older adults being frail and incapable of learning, thereby weakening a myth of ageing. Not a burden but an equal; not dependent, but independent; not incompetent, but competent.

Participants from the study made many references to increased communication based on computer discussions with intergenerational members. Clem was delighted to share new-found computer skills with her grandson and was always keen to "show off" to him particularly when she achieved something new. Clem's grandson was a welcome and frequent visitor to her home. He encouraged Clem to undertake personal challenges on the computer by sharing with her the many functions and uses of the computer.

In relation to friends and neighbours, and a sense of community, participants gave varying accounts of improvements in relationships. The reliance on close assistance when needed (help-at-hand) was identified as essential when facing difficulties and frustrations in learning. Participants spoke of greater contact with close neighbours based on computer-related needs. Neighbours provided a unique opportunity to establish and affirm the sense of community and belonging. Their geographical closeness enabled them to be of assistance to struggling learners and to share achievements. For many in the study having reliable and close assistance 
made a difference to their ability to overcome difficulties. By being able to consult with a neighbour, the participants did not have to wait until weekly lessons for problems to be solved. As was described by the participants, there were many times when they were "stuck" and just needed to know how to troubleshoot in the language they would understand.

Older people are able to enhance existing relationships with people from interest groups, particularly when members are geographically distant from one another. In the current study, Pat was able to email fellow lace-makers in-between their annual meeting. These exchanges were principally to swap patterns and to discuss lace-making generally, but increasingly the communication included personal comments. The members had more opportunities to get to know each other and their relationships were strengthened on a new level. In a similar way, Gill delighted in discovering the names of plants she had previously been unable to identify. Gill would then share this knowledge via email with other members of the gardening club. Alex said the shared interest in computing gave her other groups, such as during aquarobics and exercise classes, more to talk about.

Continued participation. The quality and strengthening of family, friend and neighbourhood relationships enabled continued and meaningful participation in life in general. Sunny described her inclusion in family discussions as a result of learning how to use a computer. In the recent past, at family gatherings, she was expected to sit quietly in the corner attending to her knitting. As a result of learning to use the computer, Sunny was able to ask questions, understand what others were talking about and feel that she was on the same level of knowledge as the rest of the group. Sunny's nephew and niece offered her unsolicited assistance with any computer problems, "Can I help, aunty?". Her contributions to computer discussions were valued, and Sunny believed she was not considered to be a little old lady asking stupid questions and not knowing what she was talking about.

The importance of meaningful participation, as experienced by the older adults in the study and affirmed by others was an essential aspect of well-being. A number of participants in the study provided details of their computer-generated contributions to social, religious, family and interest 
International Journal of Ageing and Later Life

groups and organisations. These included creating budgets using spreadsheets; designing and writing newsletters, event notices and posters using desktop publishing programs; and compiling historical and biographical documents using word processors. In all instances, it was apparent that the participant's skills and knowledge were appreciated and valued by the group and organisation members.

Interest in life generally. The participant group in the study displayed an interest and enthusiasm for life that was reflected in their learning experiences and in a cyclic way, appeared to be generative; the more they enjoyed their learning, the more they enjoyed life in general. Gill described what it was like to be a computer learner:

\footnotetext{
I've got two loves, definitely, two loves. Computers and gardening. I wondered a few weeks back which was stronger. I think gardening is stronger. But they are both pretty strong. Look, it's the most magnificent thing out. Magic. Absolute magic for me. What would I do without it? What did I do with all my time before? It's just so rewarding, fulfilling. That's how I feel. This is a labour of love. It makes me feel good. You want another life to handle it. Not here for dying. (Gill)
}

Sunny commented that she was "on the down run," but was going to "make the best of it with what I'm doing." Both Gill and Sunny referred to the temporal nature of life and their attitude to how they wanted to live their lives. They did not want to "fill in time" in meaningless pursuits. They were wholeheartedly committed to doing their very best in whatever they were engaged in.

Participants in the study were keen to discuss future projects and the changing nature of their goals as they became more competent in their computer use. Unanticipated opportunities opened up as the seemingly infinite nature of the computer learning environment revealed itself to them. Participants discussed the exciting possibility of future projects and fulfilling future goals and were delighted to share new-found discoveries. They were interested in the myriad of uses that people, especially those in later life, gained from the computer. Participants were amazed at the diversity of interest and how the computer could be used to extend these interests. This additional knowledge awakened within them an interest in areas not thought of before. The later life computer learners in the study reflected on how older people use the computer for many and varied 
purposes and this reflection enabled them to show more interest in life in general. They began to see other possible uses for the computer and this ability to respond to the changing nature of the world enabled them to broaden their horizons and expand their lifeworld and increased their ability to adapt to ongoing changes.

\section{Summary and Conclusion}

The conceptual frameworks from the literature of ageing well provided a sound basis for the analysis of data from the research and the establishment of links and relationships between many components and dimensions of well-being as they related to the learning experience of later life computer learners. The frameworks have been useful in setting a context for the notion that ageing is a process and that there are no inevitabilities about the ageing process. Analysis suggested that older adult computer learners in the study were influencing the direction their lives would take. They were learning their lives into the future and determining the type of life they wanted for themselves while maintaining a sense of self, of integrity and continuity. Later life learners were developing in new and unforeseen ways, embracing change and growth.

Ageing was seen as developmental and evolutionary. During older adulthood, there was no evidence from the study of participants being aware of a state of oldness, at least not in a way that restricted their life, choices and the ability to act. The participants generally had positive attitudes to ageing or at least did not bring negative attitudes to learning as a result of ageing. They had a sense of agency and a belief in themselves that they could act and that these actions would be productive, positive and self-affirming. They were positioning themselves favourably to act and to be in control of their lifeworld.

The hermeneutic phenomenological methodology and analysis from the study helped uncover the deep need and yearning from within the being to relate to others, to feel a sense of belongingness and to participate and contribute with others in meaningful and valued ways. Participants in the study provided many instances of care for others and the pleasure of inclusion. They showed immense joy in being able to share the ups and downs of the learning experience. Also, in a technological 
International Journal of Ageing and Later Life

world with the potential for alienation, the older adult computer learners in the study embraced the need for change. They achieved a great deal of satisfaction from better understanding their lifeworld and playing an important part in it.

The later life computer learners in the study viewed computer learning as a path to self-actualisation and also as a way of being able to represent the self in authentic ways. Participants wanted connectedness with others and depth in their lives. They valued relationships and feeling a part of the world and sought unity with the self and others. It is human to want to have something to think about: to get dressed up to go somewhere; to do things that are meaningful and fulfilling. Humans of all ages want to have depth to their lives and to feel useful and valued.

The people in the study sought compatibility between thoughts and actions (sense of agency) and beliefs and emotions (relationships). The notion of the being as an entity that is becoming (growing and developing) and belonging (with others) was an important aspect of the study. Participants were being, becoming and belonging in the pursuit of the existential self. They pursued opportunities to be true to their sense of self and to have their intrinsic needs actualised. They looked for ways to use ICTs that were relevant in their lifeworld and that would reflect how they wanted to live their lives and the meaning in their lives. They did not slavishly follow the popular interests of others; rather, they learnt skills that would be useful and purposeful. For some participants, the real value was in learning, the stimulus of learning and the challenge of learning something new. In the existential pursuit of being-becomingbelonging, the older adults in the study challenged and competed against opposing actualities from the socio-cultural field.

Through learning, the participants in the study experienced increased self-confidence and a greater interest in life. The increased participation placed them in a position to counter the notion of developmental certainties of decline. The participants perceived the benefits of learning as being iterative and far-reaching, positioning them favourably to adapt to change.

The current group of older adults is unique and groundbreaking. Their parents and grandparents were unable to provide role models because the previous generations had never lived through so many technological changes. The current generation of older adults is minimising potential 
marginalisation with a strong sense of contributing to life in ways of their choosing. This does not appear to lead to selfishness or insular behaviour. While there is an element of autonomy and independence, there is also interdependence and intergenerational importance in their lives; for maintaining quality relationships with close and extended family and local community. Counter to the notion that the learning may lead to self-absorption, there may even be a greater sense of concern for the future and for passing on the culture.

Learning to use ICT and learning generally have been found to be significant for the older adults in the study in constructing a sense of well-being. The learners in the study had the strength to act and a sense of agency in new ways; ways that were not related to their past life. These ways related to modern skills, to changes, to technology, to family, friendship and the local community. The older adults in the study were aware of the pressures of the changing world and the need to adapt. However, they did not consider age as a place to stand still. Activity and participation, choice and enjoyment were of significant importance in their learning experience outcomes. They may have thought initially only of tangible outcomes or outcomes that could be measured, but on reflection they recognised intangible but possibly more important or significant outcomes for themselves. For the participants in the study, learning and a sense of well-being were inter-related, that is, learning is about living and living is about learning.

\section{Acknowledgements}

The participants in the study shared their experiences openly and honestly in a way that enables their stories to live on in the hearts and minds of others. A critical friend and mentor, Professor Sandy Schuck, provides ongoing encouragement for research and writing endeavours.

\section{Corresponding Author}

Helen Russell, Faculty of Arts and Social Sciences - Education, University of Technology Sydney, Kuring-gai Campus, PO Box 222, Lindfield 2070, Australia. Email: Helen.Russell@uts.edu.au 
International Journal of Ageing and Later Life

\section{References}

Allport, G. (1955). Becoming. New Haven: Yale University Press.

Blit-Cohen, E. \& Litwin, H. (2004). Elder participation in cyberspace: A qualitative analysis of Israeli retirees. Journal of Aging Studies 18: 385-398.

Borglin, G., Edberg, A.-K. \& Hallberg, I. R. (2005). The experience of quality of life among older people. Journal of Aging Studies 19(2): 201-220.

Candy, P. C. (1991). Self-direction for lifelong learning: A comprehensive guide to theory and practice. San Francisco: Jossey-Bass.

Centre for Health Promotion. (2010). The quality of life model. Available on http:/ / www.utoronto.ca/qol.concepts.htm (Accessed: April 17, 2010).

Czaja, S. J., Charness, N., Fisk, A. D., Hertzog, C., Nair, S. N., Rogers, W. A. \& Sharit, J. (2006). Factors predicting the use of technology: Findings from the center for research and education on aging and technology. Psychology and Aging 21(2): 333-352.

Erikson, E. H., Erikson, J. M. \& Kivnivk, H. Q. (1986). Vital involvement in old age. New York: W. W. Norton.

Frankl, V. E. (1984). Man's search for meaning. New York: Washington Square Press.

Heidegger, M. (1962). Being and time (J. Macqaurie \& E. Robinson, Trans.). Oxford: Blackwell.

Hernandez-Encuentra, E., Pousada, M. \& Gomez-Zuniga, B. (2009). ICT and older people: Beyond usability. Educational Gerontology 35(3): 226-245.

Hrimech, M. \& Bouchard, P. (1998). Spontaneous learning strategies in the natural setting: Learning how to use computers. In H. B. Long. \& Associates (eds.), Developing paradigms for self-directed learning (pp. 27-44). Oklahoma: University of Oklahoma.

Ihde, D. (1990). Technology and the lifeworld: From garden to earth. Bloomington: Indiana University Press.

Jarvis, P. (2001). Learning in later life: An introduction for educators $\mathcal{E}$ carers. London: Kogan Page.

Kelly, J. R. (1993). Introduction. In J. R. Kelly (ed.), Activity and aging: Staying involved in later life. Newbury Park, CA: Sage. 
Kidd, J. R. (1973). Relentless verity. Education for being-becoming-belonging. Syracuse, NY: Syracuse University.

Mahmood, A., Yamamoto, T., Lee, M. \& Steggell, C. (2008). Perceptions and use of gerontechnology: Implications for aging in place. Journal of Housing for the Elderly 22(1): 104-126.

Moody, H. R. (1986). Late life learning in the information society. In D. A. Peterson, J. E. Thornton \& J. E. Birren (eds.), Education and aging (pp. 122-143). Englewood Cliffs, NJ: Prentice-Hall.

Mynatt, E. D. \& Rogers, W. A. (2001). Developing technology to support the functional independence of older adults. Ageing International 27(1): $24-41$.

Organisation for Economic Co-operation and Development (OECD) (2001). The well-being of nations: The role of human and social capital. Available on http://www.oecd.org (Accessed: April 4, 2004).

Organisation for Economic Co-operation and Development (OECD) (2003). OECD publication identifies key competencies for personal, social, and economic well-being. Available on http://www.oecd.org (Accessed: April 17, 2010).

Rogers, C. R. (1969). Freedom to learn. Columbus: Merrill.

Slegers, K., van Boxtel, M. \& Jolles, P. (2007). The effects of computer training and internet usage on the use of everyday technology for older adults: A randomized controlled study. Educational Gerontology 33(2): 91-110.

Thorson, J. A. (1978). Future trends in education for older adults. In R. H. Sherron \& D. B. Lumsden (eds.), Introduction to educational gerontology (pp. 201-227). Washington, DC: Hemisphere.

TSAO Foundation. (2004). The structure of successful ageing. Available on http://www.tsaofoundation.org/articles/successful04.html (Accessed: April 5, 2004).

Wolf, M. A. (1998). New approaches to the education of older adults. In J. C. Fisher \& M. A. Wolf (eds.), Using learning to meet the challenges of older adulthood (pp. 20-36). San Francisco: Jossey-Bass.

World Health Organization (WHO) (2002). Active ageing: A policy framework. Available on http://www.who.int/hpr/againg/ActiveAgeing PolicyFrame.pdf (Accessed: April 4, 2004). 